\title{
LH, Rat Strain
}

National Cancer Institute

\section{Source}

National Cancer Institute. LH, Rat Strain. NCI Thesaurus. Code C14408.

$\mathrm{LH}$ : The strain exhibits mild hypertension (approx $165 \mathrm{mmHg}$ in males and $140 \mathrm{mmHg}$ in females at 14 weeks of age in 1984) with increased body weight and plasma lipids. There is reduced life-span (compared with LN and LL) with histopathological lesions characteristic of hypertensive disease in rats. 